\title{
The energy aspect of material property in WEDM and its application
}

\author{
Y.S. Liao ${ }^{\mathrm{a}, *}$, Y.P. Yu ${ }^{\mathrm{b}}$ \\ a Department of Mechanical Engineering, National Taiwan University 1, Sec. 4, Roosevelt Rd, Taipei 106, Taiwan \\ ${ }^{\mathrm{b}}$ Department of Mechanical Engineering, Hwa-Hsia College of Technology and Commerce, No. 111, Huashin St., Junghe City, Taipei 235, Taiwan
}

Accepted 30 October 2003

\begin{abstract}
The relationship between machining parameters and machining characteristics of different materials in WEDM is difficult to obtain because a large number of experiments must be conducted repeatedly. A new concept attempting to solve this problem is presented in this paper. The specific discharge energy (SDE) defining as the real energy required to remove a unit volume of material is proposed. The SDE is constant for a specific material. Experimental results reveal that the relative relationship of SDE between different materials is invariant as long as all materials are machined under the same machining conditions. It is also found that the materials having close value of SDE demonstrate very similar machining characteristics such as machining speed, discharge frequency, groove width and finish of the machined surface under the same machining conditions. This result can be applied for the determination of the settings of machining parameters of different materials.
\end{abstract}

(C) 2004 Elsevier B.V. All rights reserved.

Keywords: WEDM; Specific discharge energy; Machining parameters

\section{Introduction}

There are different machining characteristics, including machining speed, roughness of the machined surface, groove width, discharge frequency, abnormal discharge ratio, under different machining conditions in WEDM. Different materials even when they are machined under the same machining conditions would result in different machining characteristics. It is difficult to control and predict the machining characteristics in WEDM. There are very few studies on this subject so far. The studies concerned with materials are almost of all stressed on the effect of electrode material on machinability in WEDM or die sinking EDM [1,2]. Levy and Maggi [3] had compared the influence of material properties of different steels on machining characteristics, but only limited to qualitative discussions. The material properties such as melting point, density, specific heat, thermal conductivity, yield strength, etc. all should have effects on machining characteristics. It is extremely difficult to conclude and pinpoint a concise and definite physical quantity that can fully reflect the material properties in WEDM, and use it to predict machining characteristics. In general, the material removal rate and machining characteristics during

\footnotetext{
* Corresponding author. Tel.: +886-2-2362-6431; fax: +886-2-2363-1755.

E-mail address: liaoys@ntu.edu.tw (Y.S. Liao).
}

the WEDM process depend on the distribution of the energy supplied to the gap by the electrical current. Various thermal models proposed for EDM [4-7] had shown that the complexities and the stochastic nature of multiple discharges render difficulties in analyzing the process theoretically. From the energy point of view, a quantity defining as the real energy required to remove a unit volume of a specific material in wire electrical discharge machining and coined by SDE is proposed in the paper. The SDE should be constant for a given material, and it is considered as one of the material properties in WEDM. The SDEs of different materials are compared first in the paper. Materials having close values of SDE are selected, and their machining characteristics under identical machining conditions are evaluated and compared. Based on the finding of the property of SDE with respect to different materials, a potential application of SDE is described. Finally a few conclusions are drawn.

\section{Theory of specific discharge energy}

In wire electrical discharge machining, a metal wire is used as the electrode and de-ionized solvent as the machining liquid. A specific electrical voltage is applied to both of the electrode and workpiece. Once the gap between two electrodes is narrow enough, electrical discharge occurs. Material removal is accomplished through the thermal functions 


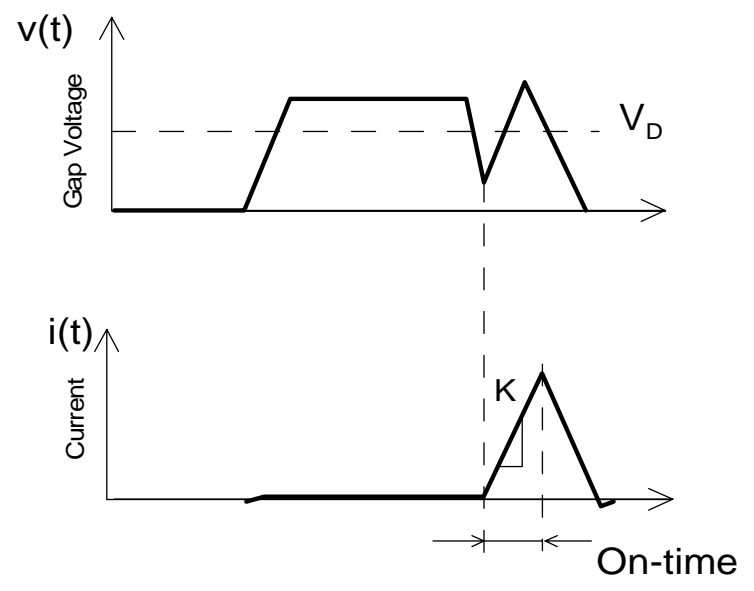

Fig. 1. Typical waveforms of voltage and current of a single discharge.

caused by the discharge, including evaporation and melting, and the function of force, including discharge impact pressure and explosive force, which expel the melted residue. Since the discharge process is a complex one, it is susceptible to the effect of a number of factors. However, from the perspective of machining energy, each pulse during the discharge process is an output of energy. The energy distribution between the workpiece and wire electrode and the actual effective removal energy should be related to the distance between the wire electrode and workpiece, flushing pressure, conductivity of the machining liquid and discharge on time.

During wire electrical discharge machining, the discharge power is determined by the single discharge energy multiplied by discharge frequency. In reality, the discharge on time $\left(T_{\text {on }}\right)$ for the same machining operation must remain constant in order to obtain uniform groove width and stable machining. Fig. 1 illustrates the typical voltage and electrical current waves resulted from the pulse generator of the machine used in the experiment. The current produced by the pulse generator has an equilateral triangle shape. If the average working voltage is $V_{\mathrm{D}}$, then the single discharge energy is given by the following equation:

$\Delta E=\int_{\text {pulse_duration }} v(\tau) i(\tau) \mathrm{d} \tau=V_{\mathrm{D}} K T_{\text {on }}^{2}$

where $K$ denotes the rising slope of the electrical current and it is one of the design parameters of the discharge power source. Its unit is A/ $\mu$ s. Different machining conditions generate different discharge frequencies. Let the discharge frequency be $F_{\mathrm{q}}$, then the discharge power $(W)$ can be expressed as

$W=F_{\mathrm{q}} \Delta E=F_{\mathrm{q}} K V_{\mathrm{D}} T_{\mathrm{on}}^{2}$

For the machine used in the experiment, there are two sets of power parameters. Normal discharge time $T_{\text {on }}$ and off time $T_{\text {off }}$ are used when the discharge is normal. They are switched to $A_{\text {on }}$ and $A_{\text {off }}$, represented abnormal discharge time and off time, respectively, when an abnormal discharge is detected. Other machining parameters include servo voltage $S_{\mathrm{v}}$, wire speed $W_{\mathrm{s}}$ and flushing pressure. Not every discharge in the actual machining process is a normal discharge. Some are arc discharges while others are short pulses. Let the ratio of abnormal discharges in the total discharges, then called abnormal ratio thereafter, be denoted by $r$. Arc discharge, based on the experimental data, usually accounts for half of the abnormal discharges, short discharge does not provide any discharge energy, hence the discharge power actually provided by the power supply denoted by $W^{\prime}$ is

$W^{\prime}=V_{\mathrm{D}} K F_{\mathrm{q}}\left(T_{\mathrm{on}}^{2}(1-r)+\frac{1}{2} A_{\mathrm{on}}^{2} r\right)$

One part of the energy supplied by power source is used to remove workpiece, the other is transmitted to wire electrode, and the rest is distributed on machining fluid. The effective energy that actually achieves workpiece removal accounts for part of total energy, and it is related to the machining parameters, electrode and work materials $[8,9]$. Let the proportion of the total energy that is actually used for metal removal be defined as discharge efficiency and denoted by $\eta$, then the effective discharge power $W^{\prime \prime}$ is

$W^{\prime \prime}=W^{\prime} \eta$

The discharge efficiency is related to materials, machining parameters and conditions of the machines. Defining the real energy needed to remove a unit volume of material during the machining process as the specific discharge energy (SDE) and denoted by $u_{0}$, then SDE can be expressed as

$u_{0}=\frac{W^{\prime \prime}}{G H F}=\frac{V_{\mathrm{D}} K F_{\mathrm{q}}\left(T_{\mathrm{on}}^{2}(1-r)+A_{\mathrm{on}}^{2} r / 2\right) \eta}{G H F}$

where $G$ is the groove width, $H$ the workpiece height, $F$ the table feed rate.

SDE should be constant for a given material irrespective to machining conditions, and it can be considered as one of the properties of a material in wire-EDM. For a given work material, the discharge efficiency would be influenced by electrode material and machining parameters. By definition, it is readily understood that the larger the SDE, the harder the material to be removed. The higher the discharge efficiency, the more energy is distributed on workpiece during machining. Since SDE is a material property, it is expected that materials having equal SDE would result in identical machining characteristics if they are machined under the same machining conditions.

Eq. (5) can also be derived from dimensional analysis point of view. Physically $u_{0}$ should be constant for a given material. All possible variables related to WEDM and their dimensions are listed in Table 1 . The quantity $\theta$ is the average temperature generated on workpiece surface. Quantities $k, \rho, c$, are the thermal conductivity, density and specific heat of work material. Similar to the traditional specific cutting energy in cutting [10], the average temperature on the surface of workpiece should be influenced by $u_{0}$ and thermal properties of the material. Since material removal rate is related to machining speed and machining groove, through 
Table 1

Dimensional analysis of physical quantities

\begin{tabular}{lll}
\hline Physical quantity & Symbol & Dimension \\
\hline Specific discharge energy & $u_{0}$ & $\mathrm{FL}^{-2}$ \\
Table feed rate & $F$ & $\mathrm{LT}^{-1}$ \\
Average temperature generated & $\theta$ & $\theta$ \\
$\quad$ & \\
on workpiece surface & $G$ & $\mathrm{~L}$ \\
Groove width & $H$ & $\mathrm{~L}^{-1} \mathrm{FLT}^{-1} \theta^{-1}$ \\
Workpiece height & $k$ & $\mathrm{ML}^{-3}$ \\
Thermal conductivity & $\rho$ & $\mathrm{FLM}^{-1} \theta^{-1}$ \\
Density & $c$ & $\mathrm{FLT}^{-1}$ \\
Specific heat & $W^{\prime \prime}$ & \\
Effective discharge power & $\mathrm{Fass}$ & $(\mathrm{M}), \mathrm{force}^{-1}$ \\
\hline
\end{tabular}

Temperature $(\theta)$, length $(\mathrm{L})$, time $(\mathrm{T})$, mass $(\mathrm{M})$, force $(\mathrm{F})$.

dimensional analysis a dimensionless equation is obtained as follows:

$\frac{\theta}{u_{0}}\left(\frac{k \rho c}{F G}\right)^{1 / 2}=C_{1}$

or

$u_{0} \sim \theta\left(\frac{k \rho c}{F G}\right)^{1 / 2}$

Considering the energy provided during wire electrical discharge machining, physical quantities related to energy are specific discharge energy, effective discharge power and temperature on the workpiece surface. Similarly, taking the workpiece height, where the energy or temperature is distributed on, into consideration, another dimensionless equation is obtained as follows:

$\frac{1}{\theta}\left(\frac{W^{\prime \prime} u_{0}}{k \rho c H}\right)^{1 / 2}=C_{2}$

or

$\theta \sim\left(\frac{W^{\prime \prime} u_{0}}{k \rho c H}\right)^{1 / 2}$

Substituting Eqs. (4) and (9) into Eq. (7) yields

$u_{0} \sim \frac{W^{\prime} \eta}{F G H}$

This is the same as the definition of specific discharge energy given previously by Eq. (5).

\section{Experiments and the analysis of results}

The first goal of the experiment is to check if SDE is constant for a given material, and to verify if the machining characteristics are identical for the materials having equal value of SED machined under the same machining conditions. The second purpose is to understand to what extent each machining parameter affects the discharge efficiency $\eta$. The experimental apparatus include a flushing type five-axis CNC wire electrical discharge machine manufactured by Ching-Hong Inc., Taiwan. The main unit is equipped with an iso-energy discharge wave power supply system that can generate triangle wave with equal slopes and peak current slope of $450 \mathrm{~A} / \mu \mathrm{s}$. The average working voltage is $80 \mathrm{~V}$. Machining parameters can be adjusted from the control panel. The wire electrode is 6-4 brass wire, $60 \%(\mathrm{Cu}), 40 \%(\mathrm{Zn})$ with a diameter of $0.25 \mathrm{~mm}$. Its tensile strength is $95-105 \mathrm{kgf} / \mathrm{mm}^{2}$ and the melting point is $930^{\circ} \mathrm{C}$. Experiments are conducted under G95 mode. In others words, servo voltage control is set in machining.

\subsection{Specific discharge energy and its relationship with machining characteristics}

According to Table 2, two sets of machining conditions are selected at first, and four materials namely aluminum (Al) alloy, titanium (Ti) alloy, stainless steel, cold work tool steel, and hot work tool steel are machined, respectively. Based on Eq. (5) the SDE of different materials are calculated individually by assuming the discharge efficiency $\eta$ equals to 1. The SDE of various materials under two sets of machining conditions are listed in Table 3 . The values in brackets are values relative to a certain material and in this case it is titanium alloy. From Table 3, it is noted that one material has different values of SDE under two different machining conditions rather than just one value as postulated. The reason is that the discharge efficiency is different under different machining conditions, but since it is unknown beforehand it is taken to be one in both cases. It is also noted that the relative relationship of SDE between different materials (i.e. the values given in the parenthesis) remains unchanged as long as they all are machined under the same machining conditions. This result also indirectly confirms our postulation that the SDE for a given material should be constant.

The next is to verify that the materials having the same SDE would have identical machining characteristics if they

Table 2

Experimental machining parameters

\begin{tabular}{lllll}
\hline Set no. & \multicolumn{2}{l}{ Machining parameter } & & \\
\cline { 2 - 5 } & Discharge on time $(\mu \mathrm{s})$ & Discharge off time $(\mu \mathrm{s})$ & Arc on time $(\mu \mathrm{s})$ & Arc off time $(\mu \mathrm{s})$ \\
\hline 1 & 0.9 & 16 & 0.5 & 18 \\
2 & 0.7 & 16 & 0.5 & 18
\end{tabular}

Other machining parameters: wire tension $1200 \mathrm{gf}$, wire speed $9 \mathrm{~m} / \mathrm{min}$, flushing pressure $20 \mathrm{~kg} / \mathrm{cm}^{2}$. 
Table 3

SDE of various materials $\left(\mathrm{J} / \mathrm{mm}^{3}\right)$

\begin{tabular}{llllll}
\hline Set no. & $\begin{array}{l}\text { Ti alloy } \\
(6061)\end{array}$ & $\begin{array}{l}\text { Supper alloy } \\
\text { (Inconel 718) }\end{array}$ & $\begin{array}{l}\text { Ti alloy } \\
(\text { Ti-6Al-4V) }\end{array}$ & $\begin{array}{l}\text { Stainless steel } \\
\text { (SUS 304) }\end{array}$ & $\begin{array}{l}\text { Cold work tool } \\
\text { steel (SKD11) }\end{array}$ \\
\hline 1 & $275(1)$ & $900(3.27)$ & $690(2.51)$ & $840(3.05)$ & $890(3.24)$ \\
2 & $225(1)$ & $730(3.24)$ & $563(2.50)$ & $690(3.07)$ & $735(3.27)$
\end{tabular}

The values given is parenthesis are the relative value between each other.

Table 4

Experimental machining parameters

\begin{tabular}{lllll}
\hline Set no. & \multicolumn{2}{l}{ Machining parameter } & & \\
\cline { 2 - 5 } & Discharge on time $(\mu \mathrm{s})$ & Discharge off time $(\mu \mathrm{s})$ & Arc on time $(\mu \mathrm{s})$ & Arc off time $(\mu \mathrm{s})$ \\
\hline 1 & 0.9 & 16 & 0.5 & 18 \\
2 & 0.7 & 16 & 0.5 & 18 \\
\hline
\end{tabular}

Other machining parameter: wire tension $900 \mathrm{gf}$, wire speed $8 \mathrm{~m} / \mathrm{min}$, flushing pressure $20 \mathrm{~kg} / \mathrm{cm}^{2}$.

Table 5

Machining characteristics of SKD11 and Inconel 718 machined under the condition set no. 1

\begin{tabular}{lllll}
\hline Material & Abnormal ratio & Machining speed & Spark frequency & Groove width \\
\hline SKD11 & 38 & 6.9 & 26.5 & 354 \\
Inconel 718 & 37 & 6.8 & 26.5 & 349 \\
\hline
\end{tabular}

Units: abnormal ratio $(\%)$, machining speed $(\mathrm{mm} / \mathrm{min})$, spark frequency $(\mathrm{kHz})$, groove width $(\mu \mathrm{m})$, surface roughness $(\mu \mathrm{m})$.

Table 6

Machining characteristics of SKD11 and Inconel 718 machined under the condition set no. 2

\begin{tabular}{lllll}
\hline Material & Abnormal ratio & Machining speed & Spark frequency & Groove width \\
\hline SKD11 & 44 & 6.3 & 32.0 & 340 \\
Inconel 718 & 42 & 6.2 & 31.5 & 3.2 \\
\hline
\end{tabular}

were machined under the same machining conditions. Referring to Table 3, the two materials with similar SDE values, SKD11 and Inconel 718, are selected in this study. Their SDEs are 890 and $900 \mathrm{~J} / \mathrm{mm}^{3}$, respectively. They are machined under the same machining conditions given in Table 4. Workpiece with a thickness of $15 \mathrm{~mm}$ is used in all experiments. The other machining conditions include the flushing pressure of $20 \mathrm{~kg} / \mathrm{cm}^{2}$, wire speed of $8 \mathrm{~m} / \mathrm{min}$ and wire tension of $900 \mathrm{gf}$. The resulted machining characteristics are summarized in Tables 5 and 6 . They are: the abnormal ratio defining as the proportion of abnormal discharges out of total discharges in a particular time interval, machining speed, discharging frequency, groove width and roughness of the machined surface. As it can be seen from the tables, the values of all machining characteristics are almost the same. This indicates that materials with similar SDE values would indeed result in very similar machining characteristics as long as they are machined under the same machining conditions as expected. By this finding, it is concluded that SDE postulated in paper can fully reflect the properties of a material in wire-EDM.

One of the practical applications of this finding is to include SDE as one of a machining parameter in constructing the neural network model between machining parameters and machining characteristics. Prediction of the machining
Table 7

Experimental level settings

\begin{tabular}{lrrrl}
\hline Control factor & \multicolumn{2}{l}{ Level } & \multicolumn{2}{l}{ Unit } \\
\cline { 2 - 3 } & \multicolumn{1}{c}{2} & 3 & \\
\hline Thickness, $H$ & 10 & 50 & & $\mathrm{~mm}$ \\
Discharge on time, $T_{\text {on }}$ & 3 & 5 & 7 & $0.1 \mu \mathrm{s}(1-9 \mathrm{steps})$ \\
Discharge off time, $T_{\text {off }}$ & 20 & 35 & 50 & $1 \mu \mathrm{s}(8-50 \mathrm{steps})$ \\
Arc on time, $A_{\text {on }}$ & 2 & 3 & 4 & $0.1 \mu \mathrm{s}(1-5 \mathrm{steps})$ \\
Arc off time, $A_{\text {off }}$ & 20 & 35 & 50 & $1 \mu \mathrm{s}(9-50 \mathrm{steps})$ \\
Servo voltage, $S_{\mathrm{v}}$ & 40 & 55 & 70 & $\mathrm{~V}(35-70 \mathrm{~V})$ \\
Wire speed. $W_{\mathrm{s}}$ & 5 & 7 & 10 & $1-16 \mathrm{~m} / \mathrm{min}(0-15 \mathrm{steps})$ \\
Flushing pressure, $F_{\mathrm{w}}$ & 3 & 5 & 7 & $0-20 \mathrm{~kg} / \mathrm{cm}^{2}(0-7 \mathrm{steps})$ \\
\hline
\end{tabular}

Table 8

Influences of the machining parameters on machining characteristics

\begin{tabular}{lllllllll}
\hline $\begin{array}{l}\text { Machining } \\
\text { characteristic }\end{array}$ & $H$ & $T_{\mathrm{on}}$ & $T_{\text {off }}$ & $A_{\mathrm{on}}$ & $A_{\mathrm{off}}$ & $S_{\mathrm{v}}$ & $W_{\mathrm{s}}$ & $F_{\mathrm{W}}$ \\
\hline $\begin{array}{l}\text { Abnormal ratio } \\
\text { Groove width }\end{array}$ & & & & & &
\end{tabular}

$(\diamond)$ most significant factor; $(\diamond)$ significant factor; $(\diamond)$ less significant factor. 
Table 9

Variation of machining characteristics with respect to significant machining parameters

\begin{tabular}{lllllll}
\hline Machining parameter & Abnormal ratio & Groove width & Machining speed & Surface roughness & Spark frequency & Discharge efficiency \\
\hline$H$ & $\nearrow$ & $\nearrow$ & $\nearrow$ & $\nearrow$ & $\searrow$ \\
$T_{\text {on }}$ & $\nearrow$ & $\nearrow$ & $\searrow$ & $\searrow$ & \\
$T_{\text {off }}$ & $\nearrow$ & $\nearrow$ & & $\searrow$ & $\searrow$ \\
$A_{\text {on }}$ & $\searrow$ & $\nearrow$ & $\searrow$ & & $\searrow$ \\
$A_{\text {off }}$ & $\searrow$ & $S_{\mathrm{v}}$ & $\nearrow$ & $\searrow$ & $\searrow$ \\
\hline
\end{tabular}

$(\nearrow)$ machining characteristics increasing; $(\searrow)$ machining characteristics decreasing.

characteristics of different materials having different SDE can then be accomplished through the network. Once the neural network model is established, it can be applied for process planning. However, this work is beyond the scope of this paper and is not reported here.

\subsection{Effect of machining parameters on discharge efficiency}

On the aspect of discharge efficiency, there is different discharge efficiency under different machining conditions. After considering realistic machining conditions, all possible variables that may have effect on discharge efficiency are selected as the control factors in the experiment. They are workpiece thickness, discharge on time, discharge off time, arc on time, arc off time, wire speed, flushing pressure and servo voltage. Since there are too many control factors, the number of experiments becomes so large that it would not be possibly affordable both in terms of cost and time if three levels were chosen for each factor. Thus, the L18 mixed orthogonal table of the Taguchi quality design method [11] is adopted. The level settings for all factors in the experiment are listed in Table 7. The machining characteristics under study are: groove width, machining speed, discharge frequency, abnormal ratio, roughness of the machined surface, and discharge efficiency. It should be noted that discharge efficiency for a machining condition is unknown in practice. Hence, for analysis purpose, the relative value with respect to a standard value is computed. In our case, the machining condition of $T_{\mathrm{on}}=0.9 \mu \mathrm{s}, S_{\mathrm{v}}=50 \mathrm{Vis}$ taken as the standard. By considering the SDE for a material is constant, and the discharge efficiency equals to 1 under the standard machining condition, the relative value of discharge efficiency under different machining condition can be computed. After conducting the experiments, the signal to noise $(\mathrm{S} / \mathrm{N})$ ratios are computed, and the analysis of variance is employed to find the significant factors affecting each machining characteristics. The results are given in Table 8 . In addition, the trends in the variations of machining characteristics with respect to each significant machining parameter are plotted and shown in Table 9.

Referring to Table 8, it is found that discharge on time and servo voltage are two most significant factors affecting the discharge efficiency $\eta$. The larger the discharge on time, the lower the discharge efficiency. Since the amount of input energy depends strongly on the discharge on time, this implies that given a high energy during the machining process, the percentage of effective energy that actually reaches the workpiece and removes the material declines significantly. Similar conclusion had also been found previously by others [12-15]. For the effect of servo voltage, a greater servo voltage results in lower discharge efficiency. The reason is that servo voltage reflects the distance between the wire electrode and workpiece. The shorter the distance between the wire electrode and the workpiece, the more likely a higher percentage of effective energy would achieve material removal. In other words discharge efficiency is negatively correlated with the distance between the wire electrode and the workpiece.

\section{Conclusions}

A new concept of specific discharge energy (SDE) is presented in the paper. It is found that this quantity is a material property in WEDM. The relative relationship of SDE between different materials is fixed as long as these materials are machined under the same machining conditions. Materials having similar value of SDE display very similar machining characteristics if they are machined under the same machining condition. Under steady machining process, the smaller discharge gap results in higher discharge efficiency. The shorter the normal discharge on time, the higher the discharge efficiency. Finally, using the characteristics of SDE, determination of parameters setting of different materials can be greatly simplified, and this work is under way.

\section{References}

[1] J. Prohaszka, A.G. Mamalis, N.M. Vaxevanidis, The effect of electrode material on machinability in wire electro-discharge machining, J. Mater. Process. Technol. 69 (1997) 233-237.

[2] P.M. Lonardo, A.A. Bruzzone, Effect of flushing and electrode material on die sinking EDM, Ann. CIRP 48 (1) (1999) 123-126.

[3] G.N. Levy, F. Maggi, WED machinability comparison of different steel grades, Ann. CIRP 39 (1) (1990) 183-185.

[4] S.M. Pandit, K.P. Rajurkar, A stochastic approach to thermal modelling applied to electro-discharge machining, Trans. ASME J. Heat Trans. 105 (1983) 555-558. 
[5] G. Spur, J. Schönbeck, Anode erosion in wire-EDM-a theoretical model, Ann. CIRP 42 (1) (1993) 253-256.

[6] R. Snoeys, F. Van Dijck, Investigation of EDM operations by means of thermo-mathematical models, Ann. CIRP 20 (1) (1971) 35-36.

[7] M. Jennes, R. Snoeys, Comparison of various approach to model the thermal load on the EDM-wire electrodes, Ann. CIRP 33 (1) (1984) 93-98.

[8] W. König, Material removal and energy distribution in electrical discharge machining, Ann. CIRP 24 (1) (1975) 95-100.

[9] M. Motoki, K. Hashiquchi, Energy distribution at the gap in electric discharge machining, Ann. CIRP 14 (1967) 485-488.

[10] M.C. Shaw, Metal Cutting Principals, Clarendon Press, Oxford, 1984.
[11] P.J. Ross, Taguchi Techniques for Quality Engineering, McGraw-Hill, Book Company, New York, 1989.

[12] Y.F. Luo, An energy-distribution strategy in fast-cutting wire EDM, J. Mater. Process. Technol. 55 (1995) 380-390.

[13] D.D. DiBitonto, P.T. Eubank, M.R. Patel, M.A. Barrufet, Theoretical models of the electrical discharge machining process. I. A simple cathode erosion model, J. Appl. Phys. 66 (1989) 4095-4103.

[14] D.D. DiBitonto, P.T. Eubank, M.R. Patel, M.A. Barrufet, Theoretical models of the electrical discharge machining process. II. The anode erosion model, J. Appl. Phys. 66 (1989) 4104-4111.

[15] P.T. Eubank, M.R. Patel, M.A. Barrufet, B. Bozkurt, Theoretical models of the electrical discharge machining process. III. The variable mass, cylindrical plasma model, J. Appl. Phys. 73 (1993) 7900-7905. 